\title{
Positive interspecific associations consistent with social information use shape juvenile fish assemblages
}

\author{
Christopher R. HaAk (D) ${ }^{1,4}$ Francis K. C. Hui, ${ }^{2}$ Geoffrey W. Cowless, ${ }^{3}$ and Andy J. Danylchuk ${ }^{1}$ \\ ${ }^{1}$ Department of Environmental Conservation \& Intercampus Marine Science Graduate Program, University of Massachusetts Amherst, \\ 160 Holdsworth Way, Amherst, Massachusetts 01003 USA \\ ${ }^{2}$ Research School of Finance, Actuarial Studies and Statistics, Australian National University, Acton, 2601 Australian Capital \\ Territory, Australia \\ ${ }^{3}$ Department of Fisheries Oceanography, School for Marine Science and Technology, University of Massachusetts Dartmouth, 836 \\ South Rodney French Blvd., New Bedford, Massachusetts 02744 USA
}

Citation: Haak, C. R., F. K. C., Hui, G. W., Cowles, and A. J., Danylchuk. 2020. Positive interspecific associations consistent with social information use shape juvenile fish assemblages. Ecology 101(2):e2920. $10.1002 /$ ecy. 2920

Abstract. Social information obtained from heterospecifics can enhance individual fitness by reducing environmental uncertainty, making it an important driver of mixed-species grouping behavior. Heterospecific groups are well documented among fishes, yet are notably more prevalent among juveniles than more advanced life stages, implying that the adaptive value of joining other species is greater during this developmental period. We propose this phenomenon can be explained by the heightened ecological relevance of heterospecifically produced cues pertaining to predation risk and or resources, as body-size uniformity inherent in early ontogeny yields greater overlap in predator and prey guild membership across juveniles of disparate taxa. To evaluate the putative role of information in shaping juvenile fish assemblages, we employed a joint species distribution model (JSDM), identifying nonrandom relationships among fishes collected in 785 seine hauls within the shallow littoral zones of a subtropical island. After accounting for species-environment relationships, which explained $39 \%$ of observed covariation in the abundance of 11 taxa, we detected high rates of positive association ( $84 \%$ of significant correlations) predominantly between mutual foraging guild members, consistent with assemblage patterns predicted to evolve under widespread interspecific information use. Affiliations occurred primarily between species characterized by neutral (i.e., noninteracting) or negative (i.e., predator-prey) relationships in later life stages, supporting the notion that heightened niche overlap due to body size homogeneity acted to increase the pertinence of information among juveniles. Taxa exerted varying degrees of influence on assemblage structure; however Eucinostomus spp., a gregarious generalist with exceptional information-production potential, had an effect several times that of all other species combined, further evidencing the likely role of information in motivating observed relationships. Co-occurrence and qualitative behavioral data inferred from remote underwater video surveys reinforced these conclusions. Collectively, these results suggest that positive interactions linked to information exchange can be among the principal factors organizing juvenile fish assemblages at local scales, highlighting the role of ontogeny in mediating the relevance and exploitation of information across species.

Key words: interspecific information transfer; social information; heterospecific association; juvenile fish; mixed-species groups; positive interactions; ontogenetic niche.

\section{INTRODUCTION}

Despite an established bias towards the importance of competition in structuring organismal assemblages, there is growing recognition that positive species interactions can be equally consequential in shaping communities, ameliorating environmental stress and facilitating coexistence among competitors (Bertness and Callaway

Manuscript received 13 September 2018; revised 12 June 2019; accepted 23 August 2019. Corresponding Editor: Jay R. Rooker.

${ }^{4}$ E-mail: chrishaak@gmail.com
1994, Bruno et al. 2003). Concurrently, a heightened awareness of the extent to which biotic interactions can act across scales to affect community structure has prompted recent calls for their integration into species distribution models, to improve predictions of the way ecosystems will respond to accelerating environmental change (Araújo and Luoto 2007, Kissling et al. 2012, Wisz et al. 2013).

One form of interaction with broad implications for community structure is participation in mixed-species groups (Goodale et al. 2017), members of which generally profit from the foraging and antipredator 
advantages associated with monospecific groups (Krause and Ruxton 2002) while also avoiding some of their pitfalls, such as intraspecific competition. Although the benefits of group participation have historically been attributed in large part to risk dilution, predator confusion, and other intrinsic properties of being among high densities of individuals (Hamilton 1971, Foster and Treherne 1981, Landeau and Terborgh 1986), there is increasing acknowledgment that these mechanisms do not adequately account for patterns of heterospecific association observed in nature (Wolters and Zuberbühler 2003, Schmidt et al. 2010); for example, the disproportionately large effect exerted by certain taxa, often referred to as "nuclear" or "sentinel" species, on the formation and cohesion of groups (Goodale and Kotagama 2005, Srinivasan et al. 2010).

Rather, a growing consensus indicates that access to socially acquired knowledge about one's surroundings, procured by observing others and their interactions with the local environment, is among the primary drivers of grouping behavior (Seppänen et al. 2007, Goodale et al. 2010, Gil et al. 2017). This "social" or "public" information, typically inferred from deliberate or more commonly inadvertent behavioral or chemical cues, can improve decision making by reducing uncertainty about basic ecological variables such as the distribution of resources or the risk of predation (Dall et al. 2005, Blanchet et al. 2010), ultimately enhancing individual fitness (McNamara and Dall 2010). Although it has proven difficult to isolate the respective roles of information-related and intrinsic mechanisms in generating the fitness benefits that incentivize grouping (Dehn 1990, Beauchamp 2017), quantitative theoretical models have shown that access to social information augments fitness across a wide variety of ecological contexts, elevating it to levels significantly above those attained through numerical benefits alone, with extensive implications for grouping and individual vigilance behavior (Gil et al. 2017).

It therefore is not likely by coincidence that the attributes typifying many attractive nuclear or sentinel species (Goodale and Kotagama 2005, Srinivasan et al. 2010) correspond closely with the characteristics that confer a high capacity for information production (Goodale et al. 2010), intimating that the attractiveness of these animals is related to their efficacy as informants (Goodale and Kotagama 2008, Hetrick and Sieving 2012). For example, several birds and fishes improve their foraging success by affiliating with species whose sensory physiology makes them particularly efficient at locating resources (Buckley 1996, Sazima et al. 2006). Meanwhile, many birds and mammals reduce their vulnerability to predation by "eavesdropping" on risk-related cues produced by heterospecifics whose ecology or morphology makes them uncommonly adept at identifying approaching threats (Goodale and Kotagama 2005, 2008), seemingly valuing the vigilance of these species over that of conspecifics (Schmitt et al. 2016).
However, the procurement of social information is not without costs, and the application of unreliable or incompatible information can precipitate maladaptive decisions (Giraldeau et al. 2002, Searcy and Nowicki 2005, Magrath et al. 2015). The ultimate value of information reflects a trade-off between the expense of acquisition and its relevance or salience for the receiver, which is inversely related to the ecological and spatiotemporal distance between individuals (Seppänen et al. 2007). Accordingly, the most valuable and thus attractive informants should be functionally or phenotypically similar neighbors sharing mutual resources and/or predatorsthat is, species occupying similar niches. In turn, the transfer of information across taxa should bring about predictable patterns of assemblage at local scales, distinguished by high frequencies of co-occurrence among ecologically similar species, as animals aggregate near others that produce cues they can exploit (Seppänen et al. 2007, Sridhar et al. 2012, Hua et al. 2016) — a structure effectively the inverse of that expected in communities governed by competition (Dayan and Simberloff 2005).

Of the traits that define an individual's phenotype or ecological niche, body size may be the most fundamental, with sweeping ramifications for physiology, mobility, and trophic position (Peters 1986, Hildrew et al. 2007). Heterogeneity in body size is often regarded as a means of niche differentiation, promoting coexistence by reducing overlap through size-dependent controls on resource utilization (Wilson 1975, Basset 1995); conversely, size homogeneity can heighten congruency in resource use and in the threat posed by predators (Woodward and Hildrew 2002, Leyequién et al. 2007). As such, body-size differential is routinely used to approximate niche overlap and to infer the types and strengths of pairwise interactions in size-structured communities (Wissinger 1992, Gravel et al. 2013). For most animals, body size is inextricably linked with developmental stage, and in few taxa is this relationship more striking than it is among fishes, for whom ontogenetic changes in body size can span several orders of magnitude. Thus, in the strongly size- or stage-structured trophic webs characteristic of aquatic environments, ontogeny can be of even greater importance than phylogeny in defining a fish's functional role or ecological niche (Kohda et al. 2008, Rudolf and Rasmussen 2013a), impacting the applicability and subsequent profitability of socially acquired information.

Interspecific information transfer occurs among fishes in the context of both foraging (Coolen et al. 2003, Karplus et al. 2007) and predator avoidance (Mathis and Smith 1993, Mirza 2003), and is likely a key factor motivating mixed-species groups of coral reef inhabitants, which decide when to feed and/or flee approaching predators based on the behaviors (e.g., patch entries or departures) and perceived densities of heterospecifics (Gil and Hein 2017, Hein et al. 2018). Although heterospecific association in fishes occurs throughout ontogeny, it is notably more prevalent between juveniles 
(Lukoschek and McCormick 2000, Overholtzer and Motta 2000, Moland et al. 2005), whose small body sizes are intrinsically more uniform and less variable when contrasted with those of more advanced developmental stages, whose sizes vary widely across species and are often plastic (Gust et al. 2002). We propose that the relative preponderance of mixed-species grouping behavior among juvenile fishes can be explained by the heightened adaptive significance of heterospecifically derived social information use during this life stage, when inherent homogeneity in body size correlates with ecological niche convergence, increasing the relevance of risk and resource-related cues between distinct taxa and expanding the pool of species from which pertinent knowledge may be obtained.

To evaluate the putative influence of information use on heterospecific associations among juveniles empirically, we examined the structure of fish communities in subtropical inshore habitats, where a diverse array of fishes utilize shallow littoral zones during early ontogeny (Parrish 1989, Nagelkerken et al. 2000). Spanning a range of trophic guilds, from piscivorous apex predators to benthic invertivores and pelagic planktivores, these fishes vary greatly in size and in habitat use as adults, yet exhibit a high degree of overlap in space, time, and body size as juveniles (Serafy et al. 2003, Mateo and Tobias 2004, Newman et al. 2007). Therefore, while interactions between adults of these taxa are typically negative (e.g., predator-prey) or nonexistent, the potential exists for the exchange of ecologically relevant information among juveniles, likely entailing: (1) threat-related behavioral cues, in the form of patch entries/departures or alarm responses, communicating the riskiness of a patch or providing advance warning of predator attack; and (2) resource-related cues or public information inferred from the foraging behavior or performance of others, telegraphing the location of prey or the quality of a given patch.

Species' co-occurrence or correlations in abundance are frequently used to identify pairwise associations and patterns of community assemblage (Gotelli and McCabe 2002, Ulrich and Gotelli 2010); however, deducing the nature of underlying relationships is a complex task, because species associations can arise through distinct mechanisms that are often hard to disentangle (Kissling et al. 2012, Morueta-Holme et al. 2016). Although positive correlations in abundance may signify facilitative interactions, they can also exist in the absence of interaction, as animals with analogous traits occupy the habitats to which they are best adapted (Keddy 1992, Webb et al. 2002); hence the inference of interactions from raw correlations can be misleading. The emerging statistical approach of joint species distribution models (JSDMs; Pollock et al. 2014) offers a means of discriminating between these different drivers of association, permitting more accurate assessment of species interactions by controlling for correlation induced by environmental filtering (Golding et al. 2015, Ovaskainen et al. 2017).
We employed a JSDM to identify associational patterns among several species of juvenile fishes, determining whether observed assemblage structure was consistent with that predicted to arise under ecologically extended social information use. Following Seppänen et al. (2007), we expected that comparatively high rates of interspecific information transfer would be evidenced by a correspondingly elevated incidence of positive nonrandom correlations in species abundance, with these relationships being stronger or more frequent between mutual guild or functional group members. Likewise, if ontogenetic constraints on body size acted to enhance the relevance of information among juveniles relative to more mature life stages, we anticipated that positive associations would be evident between taxa that were unlikely to exhibit such relationships as adults. Finally, we postulated that if access to information was among the key factors stimulating heterospecific association, then species exerting an exceptionally large influence on assemblage structure (i.e., acting in a nuclear role) would display traits consistent with high information-production potential, following Goodale et al. (2010).

\section{Methods}

\section{Data collection}

Community abundance data.-Data on the composition of juvenile fish assemblages were collected at 21 distinct stations situated within the shallow littoral zones of Eleuthera Island in The Bahamas Archipelago (Fig. 1). Spanning approximately $40 \mathrm{~km}$ along the windward and leeward coasts, sampling stations represented a diverse mosaic of habitat types including beaches, sandflats, seagrass beds, and mangrove creek systems, capturing a broad range of variation in physical and biological conditions. Stations were sampled repeatedly between January 2012 and April 2013, using a $15.2 \times 1.2 \mathrm{~m}, 3.2 \mathrm{~mm}$ mesh bagless beach seine hauled roughly parallel to shore for $20 \mathrm{~m}$, constituting a total sweep area of approximately $210 \mathrm{~m}^{2}$ per sample. Upon the completion of each haul, the proportion of swept area comprising moderate-to-dense benthic vegetation, as defined by Harborne et al. (2008), was estimated and recorded, as were the minimum and maximum depths encountered and the proximity to the mangrove fringe (up to $100 \mathrm{~m}$ ). Ambient water temperature was measured with a handheld thermometer, and the location of each seine haul was recorded using a portable GPS unit. Following each sampling event, captured specimens were identified to the lowest possible taxon (genus or species) and enumerated before being released. Individuals exceeding $\approx 150 \mathrm{~mm}$ in total length (TL) were noted and immediately released on site. For smaller specimens $(<150 \mathrm{~mm}$ TL), a representative subsample of up to 30 individuals of each taxon was retained from a subset of seine hauls and sacrificed to permit more precise identification and 
measurement. Additional details on sampling methodology and the study area can be found in Haak et al. (2019).

Environmental covariates. - To accommodate the diversity of fishes collected, and the likelihood that species with varying ecologies and functional roles may be influenced by distinct environmental factors, we considered an extensive array of independent predictors quantifying variation in biotic and abiotic habitat characteristics over a range of scales. Physical covariates included basic parameters such as water temperature and depth, as well as several measures of flow-related environmental stress arising because of incident waves and tidal currents, obtained from hydrodynamic models as outlined in Haak et al. (2019). Biological predictors reflected both microhabitat characteristics and the arrangement of the broader seascape, comprising the coverage of benthic vegetation within the sampled area and its proximity to adjacent mangrove and coral reef habitats. Temporal fluctuations in species abundance were accounted for via the inclusion of a seasonal covariate. The complete suite of explanatory environmental variables is defined in

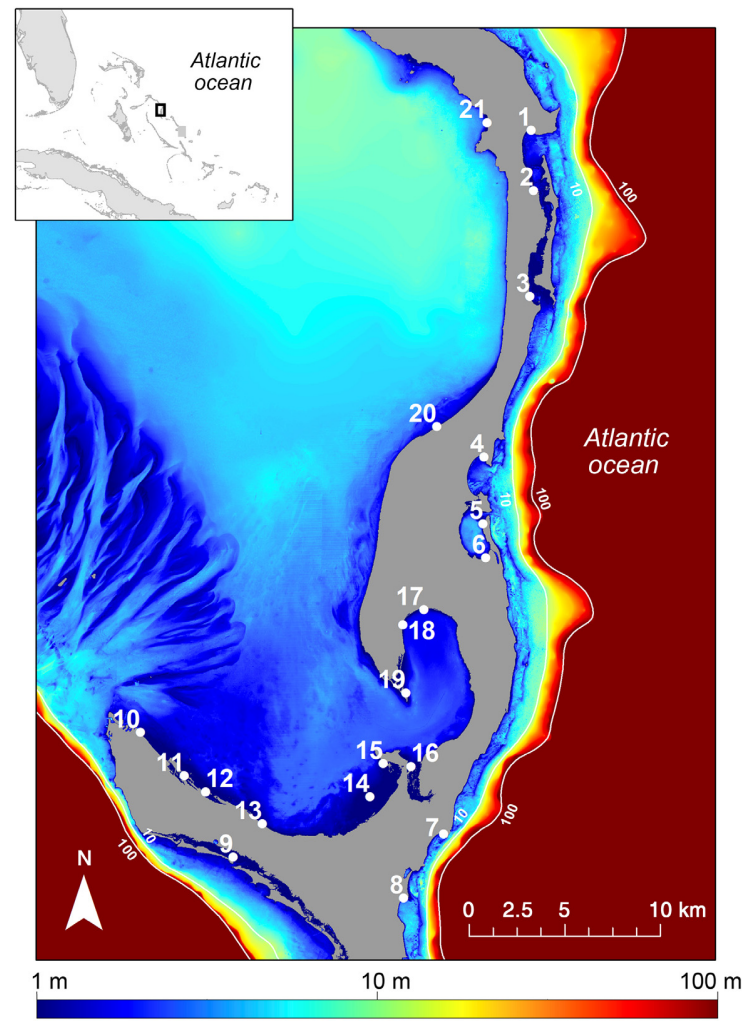

FIG. 1. Map depicting the locations of 21 stations on Eleuthera Island, The Bahamas, where community abundance data were obtained by beach seine sampling. Gray shading signifies land, and the color gradient ramp represents $\log _{10}$-transformed bathymetry $(\mathrm{m})$, truncated to a maximum depth of $100 \mathrm{~m}$. The 10 and $100-\mathrm{m}$ isoclines are included for reference.
Table 1, and additional information detailing their measurement or estimation, as well as the rationale for their inclusion, is provided in Appendix S1.

\section{Statistical analysis}

Joint species distribution model. - The present study employs a JSDM in the form of a latent variable model that approximates correlation in species' abundances via their associations with underlying "latent" gradients, treated as random variables (Hui et al. 2015, Warton et al. 2015). By explicitly modeling this correlation and estimating relationships with environmental predictors for multiple species concurrently, JSDMs permit the partitioning of observed correlation into that which can be

TABLE 1. Summary of the environmental predictors that were included as covariates in the joint species distribution model (JSDM). Details on the selection and measurement of predictors are available in Appendix S1.

\begin{tabular}{|c|c|}
\hline & Environmental predictors \\
\hline$\overline{U_{\max }}$ & $\begin{array}{l}\text { Long-term (4 yr) near-maximal (99th } \\
\text { quantile) wave bottom orbital velocity, } \\
\text { estimated by hydrodynamic models } \\
\text { described in Haak et al. (2019) }\end{array}$ \\
\hline$U_{\text {anom24 }}$ & $\begin{array}{l}\text { Wave bottom orbital velocity anomaly, or } \\
\text { the instantaneous departure from long- } \\
\text { term ( } 4 \text { yr) mean conditions in the } 24 \mathrm{~h} \\
\text { prior to sampling, estimated by } \\
\text { hydrodynamic models described in Haak } \\
\text { et al. (2019) }\end{array}$ \\
\hline$U_{\text {tide }}$ & $\begin{array}{l}\text { Maximum tidal flow velocity associated } \\
\text { with the } \mathrm{M}_{2} \text { (principal diurnal) tidal } \\
\text { constituent at a height of } 5 \mathrm{~cm} \text { above the } \\
\text { seabed, estimated by hydrodynamic models } \\
\text { described in Haak et al. (2019) }\end{array}$ \\
\hline Water depth & $\begin{array}{l}\text { Mean water depth }(\mathrm{cm}) \text { sampled by each } \\
\text { seine haul, approximated by averaging the } \\
\text { minimum and maximum depths } \\
\text { encountered at the time of sampling. }\end{array}$ \\
\hline $\begin{array}{l}\text { Mangrove } \\
\text { proximity }\end{array}$ & $\begin{array}{l}\text { Minimum distance to adjacent fringing } \\
\text { mangrove habitats (up to a maximum of } \\
100 \mathrm{~m} \text { ), estimated at the time of sampling. }\end{array}$ \\
\hline $\begin{array}{l}\text { Coral reef } \\
\text { proximity }\end{array}$ & $\begin{array}{l}\text { Minimum swimming distance from the } \\
\text { geographic centroid of each seine haul to } \\
\text { the nearest coral reef habitat as depicted } \\
\text { by the United Nations Environment } \\
\text { Program coral reef database (UNEP- } \\
\text { WCMC et al., 2010), estimated using a } \\
\text { geographic information system (GIS). }\end{array}$ \\
\hline $\begin{array}{l}\text { Water } \\
\text { temperature }\end{array}$ & $\begin{array}{l}\text { Ambient seawater temperature in the } \\
\text { vicinity of each seine haul, measured with a } \\
\text { handheld thermometer (to the nearest } \\
0.1^{\circ} \mathrm{C} \text { ) at the time of sampling. }\end{array}$ \\
\hline $\begin{array}{l}\text { Benthic } \\
\text { vegetation } \\
\text { cover }\end{array}$ & $\begin{array}{l}\text { Proportion of swept area comprising } \\
\text { moderate to dense benthic vegetation } \\
\text { (primarily seagrass) cover as defined by } \\
\text { Harborne et al. (2008), visually assessed at } \\
\text { the time of sampling following Mumby } \\
\text { et al. (1997). }\end{array}$ \\
\hline Season & $\begin{array}{l}\text { Time of year that a seine haul was } \\
\text { conducted, following the common wet } \\
\text { season (May-October) and dry season } \\
\text { (November-April) convention. }\end{array}$ \\
\hline
\end{tabular}


explained by species responses to known environmental covariates (environmental correlation), and that which remains unexplained (residual correlation) and consequently may reflect biotic interactions. While species' relationships with latent variables, quantified through their respective coefficients, might ideally be presumed to represent the outcome of interactions, they may also reflect species' responses to additional, missing or unknown environmental covariates (Kissling et al. 2012, Warton et al. 2015, Ovaskainen et al. 2016). To limit the effects of unmeasured environmental heterogeneity on the estimation of species interactions, we assumed that residual variation displaying correlation within sampling stations was environmental in nature, and a random intercept at the level of station was included for each species to account for this, precluding its influence on latent variables and thus residual correlations.

Inferring biotic interactions from species abundance data is again complicated by the fact that observed correlations can reflect the results of indirect interactions, potentially masking the true nature of relationships (Harris 2016, Popovic et al. 2019). For example, two noninteracting species that share a negative relationship with a third "mediator" species may outwardly appear to exhibit a positive relationship with one another. To overcome this challenge, several authors have proposed the use of partial correlations to detect direct or "conditional" pairwise interactions by controlling for the effects of the remaining species pool (Harris 2016, Ovaskainen et al. 2016, Popovic et al. 2019). We therefore employed partial correlations, obtained through inversion of the residual correlation matrix, in addition to raw residual correlations when evaluating species relationships.

We fitted the JSDM outlined above using the R package boral (Hui 2016), which employs Monte Carlo Markov chain methods executed in JAGS (Plummer 2003) to estimate parameters (see Appendix S2 for supplemental details on the model, including its functional form). To maximize parsimony given the presence of 11 taxa, species correlations were approximated through two latent variables (testing with additional latent variables found little difference from the results obtained here). Furthermore, due to the overdispersed nature of count data for many species, a negative binomial error distribution was employed. All covariates were centered and standardized prior to model fitting. We specified uninformative normal and uniform (when appropriate, e.g., for dispersion, or variance of the random intercept for station) priors for the hyperparameters of the model. Three MCMC chains were run for 300,000 iterations each, with a burnin period of 10,000 iterations and a thinning factor of 30. Model convergence was assessed using the GelmanRubin statistic (Gelman and Rubin 1992, Brooks and Gelman 1998), the Geweke diagnostic (Geweke 1992), and visual examination of the trace plots. Dunn-Smythe residuals were inspected for evidence of violation of model assumptions following Hui (2016). After fitting, terms were deemed to be significant when their corresponding 95\% highest posterior density (HPD) intervals did not encompass zero. Analysis was limited to include only fully metamorphosed, postlarval juveniles less than $150 \mathrm{~mm}$ fork length (FL), and rare taxa occurring in less than $1 \%$ of hauls were omitted from consideration. Finally, the power of environmental predictors (including random station effects) to explain covariation in observed species abundances was estimated by comparing the trace of the residual covariance matrix of the full model (including environmental predictors and random station effects) to that of a model containing only the two latent variables, following Warton et al. (2015) and Hui (2016).

To visualize relationships between taxa (as quantified by residual and partial correlations), and to evaluate each taxon's overall influence on assemblage structure, a network approach was utilized. Because correlations do not inherently reflect the often-unbalanced nature of interspecific relationships, the residual and partial correlations between each pair of taxa were weighted by an asymmetrical association index (Araújo et al. 2011, Sridhar et al. 2013). The index is based on the simple premise that the relative influence of one taxon (A) on another taxon (B) is equivalent to the proportion of occurrences of taxon B that coincided with taxon A, and vice versa. The resulting compositional effects of each species (or node) upon the other were then applied as edge weights in a directed network. The overall influence of each species on assemblage structure, depicted by node size, was approximated following Sridhar et al. (2013) as the normalized sum of the absolute value of the weights of each node's outgoing edges, or normalized weighted out-degree (nwD out; Wasserman and Faust 1994). Because of the wide range of values, this metric was square-root transformed for the purposes of plotting. Network graphs were generated using the $\mathrm{R}$ package qgraph (Epskamp et al. 2012).

\section{RESULTS}

\section{Community sampling}

A total of 785 seine haul samples were conducted across the 21 stations between January 2012 and April 2013. Environmental parameters recorded or estimated across seine hauls are summarized in Appendix S1: Table S1. Juvenile fishes collected in samples tended to represent two distinctive functional groups: (1) bottomassociated, largely benthivorous fishes and (2) pelagically oriented planktivores, with the mean size of individuals varying little across taxa (Table 2). The most common taxa, in terms of frequency of occurrence, were Eucinostomus spp. (mojarras; $61 \%$ ), Atherinomorus stipes (hardhead silversides, 41\%), and Sphyraena barracuda (great barracuda, 21\%). As might be expected, these also tended to be among the most abundant overall, with atherinids comprising the greatest number of all 
TABLE 2. Summary statistics describing the mean catch per unit effort (CPUE), conspecific group size, frequency of occurrence, total numerical abundance, and mean size of juvenile fishes collected by seine sampling efforts. Lengths are reported as fork length (FL), with the exception of Bothus spp. and Halichoeres bivitattus, for which total lengths (TL) are presented.

\begin{tabular}{lccccc}
\hline \hline & CPUE $\pm \mathrm{SD}$ & $\begin{array}{c}\text { Individuals per occur- } \\
\text { rence } \pm \mathrm{SD}\end{array}$ & $\begin{array}{c}\text { Total occurrences }(\% \\
\text { of total) }\end{array}$ & $\begin{array}{c}\text { Total individuals }(\% \\
\text { of total) }\end{array}$ & $\begin{array}{c}\text { Length } \pm \text { SD } \\
(\mathrm{mm})\end{array}$ \\
\hline Albula vulpes & $0.3 \pm 1.4$ & $3.6 \pm 3.8$ & $57(7.26)$ & $205(0.26)$ & $58 \pm 25$ \\
Albula goreensis & $0 \pm 0.3$ & $1.7 \pm 1$ & $15(1.91)$ & $26(0.03)$ & $51 \pm 10$ \\
Eucinostomus spp. & $42.2 \pm 121.6$ & $68.8 \pm 149.3$ & $482(61.4)$ & $33,147(42.34)$ & $50 \pm 19$ \\
Sphyraena barracuda & $0.5 \pm 1.6$ & $2.5 \pm 2.6$ & $167(21.27)$ & $423(0.54)$ & $62 \pm 23$ \\
Atherinomorus stipes & $53.9 \pm 189.9$ & $131.4 \pm 279.1$ & $322(41.02)$ & $42326(54.07)$ & $33 \pm 10$ \\
Bothus spp. & $0.2 \pm 1.1$ & $2.6 \pm 3.1$ & $61(7.77)$ & $156(0.2)$ & $43 \pm 20$ \\
H. bivitattus & $0.1 \pm 0.4$ & $1.7 \pm 1.5$ & $31(3.95)$ & $54(0.07)$ & $35 \pm 4$ \\
Harengula spp. & $1.9 \pm 20.8$ & $43.6 \pm 90.3$ & $35(4.46)$ & $1,527(1.95)$ & $37 \pm 7$ \\
Caranx spp. & $0.1 \pm 0.9$ & $2.7 \pm 3.1$ & $40(5.1)$ & $106(0.14)$ & $79 \pm 14$ \\
Haemulon spp. & $0.2 \pm 2.1$ & $5.3 \pm 9.6$ & $18(2.29)$ & $153(0.2)$ & $45 \pm 11$ \\
Trachinotus falcatus & $0.2 \pm 2.6$ & $8.8 \pm 15.1$ & & $158(0.2)$ & $56 \pm 28$ \\
\hline
\end{tabular}

individuals (54\%), followed by eucinostomids $(42 \%)$ and the rarer but highly gregarious Harengula spp. (herrings, $2 \%$ ). Raw patterns of co-occurrence, which disregard the effects of environmental filtering, suggested strong relationships in the presence/absence and abundance of several taxa (Appendix S3: Table S1).

\section{$J S D M$}

All environmental covariates were significant predictors for at least two taxa, and all fishes displayed a significant relationship with one or more environmental predictors (Appendix S3: Table S2). Among these variables, benthic vegetation coverage exerted a significant effect on the greatest number of taxa $(n=7)$, although as might be expected it had little influence on more pelagically oriented fishes such as atherinids and clupeids. Basic physical parameters, such as water depth and temperature, were significantly related to the abundance of assorted demersal and pelagic fishes, as were hydrodynamic variables reflecting variation in wave and tidally driven water velocities. Swimming distance to coral reef habitats was a significant predictor for several fishes with reef-associated adult life stages, and proximity to mangroves was likewise linked to the abundance of species known to exploit fringing mangrove habitats. Seasonal shifts in abundance were also detected for some fishes.

Significant positive and negative environmental correlations were detected between several community members (Fig. 2a; Appendix S3: Table S3a), indicating that similarities and disparities in species-specific responses to explanatory variables (i.e., environmental filtering) acted in part to produce observed raw correlations in abundance. Collectively, environmental covariates, including random station effects, accounted for approximately $39 \%$ of the covariation in abundance among species. Environmental correlations tended to segregate along the lines of functional differences, with positive correlations occurring largely between fishes characterized by similar patterns of water-column utilization or foraging modes. For example, environmental preferences of the two most abundant and frequently occurring taxa, Eucinostomus spp. (a demersal benthivore) and A. stipes (a pelagic planktivore), were negatively correlated with one another, but were positively correlated with members of their respective functional groups (Albula vulpes or bonefish, and Harengula spp., respectively). Eucinostomus spp. showed the greatest number of positive environmental correlations, which may be attributed to its habitat-generalist nature. Several negative environmental correlations were observed for Trachinotus falcatus (permit), likely related to its unusual positive relationship with wave-driven water velocities.

Strong residual correlations were present between taxa after accounting for environmental preferences (Fig. 2b; Appendix S3: Table S3b). Of the 19 significant relationships identified, $16(84 \%)$ were positive, occurring primarily among fishes within a single functional group, the demersal benthivores. The strongest residual correlation was present between Eucinostomus spp. and A. vulpes, which is not surprising given that all but a single $A$. vulpes specimen co-occurred with mojarras. These two taxa also displayed the greatest number of significant residual correlations with other fishes ( $n=8$ for both), followed by S. barracuda and Bothus spp., or lefteye flounders ( $n=4$ for both). The high number of significant residual correlations observed for A. vulpes was unexpected considering the species' relative rarity and its infrequent cooccurrence with taxa other than eucinostomids; it therefore seems likely that these relationships arose as an indirect result of $A$. vulpes having a near-obligate association with Eucinostomus spp. Trachinotus falcatus was the only species to exhibit negative residual correlations, which it shared with three taxa.

Partial correlations revealed a considerably reduced set of significant interspecific associations (Fig. 2c; Appendix S3: Table S4), with only four significant relationships remaining, all but one of which involved Eucinostomus spp. Foremost among these in terms of magnitude was a pronounced positive correlation 
(A)

\begin{tabular}{|c|c|c|c|c|c|c|c|c|c|c|}
\hline A.v & & t & $\star$ & 0 & $\otimes$ & 3 & 0 & 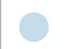 & 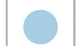 & \\
\hline 0.01 & A.g & & 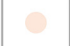 & D & & & 0 & & & \\
\hline 0.69 & -0.04 & $\mathrm{Eu}$ & * & $\theta$ & $\star$ & 0 & 0 & ( & $\otimes$ & $\forall$ \\
\hline 0.59 & -0.11 & 0.73 & S.b & $\theta$ & $\theta$ & 0 & 0 & 0 & $\otimes$ & \\
\hline .05 & 0.17 & -0.29 & -0.07 & A.s & 0 & 0 & $\star$ & 0 & 0 & \\
\hline .32 & -0.07 & 0.52 & 0.28 & -0.08 & Bot & 0 & 0 & 0 & & \\
\hline .29 & -0.05 & -0.21 & -0.14 & 0.16 & 0.16 & H.b & $\mathrm{C}$ & 0 & & \\
\hline 0.18 & 0.24 & -0.15 & -0.1 & 0.45 & -0.15 & 0.1 & Har & $\theta$ & & \\
\hline .21 & 0.24 & 0.12 & 0.22 & 0.24 & -0.14 & 0.12 & 0.31 & Car & 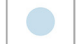 & \\
\hline 0.29 & -0.25 & 0.37 & 0.31 & -0.22 & 0.04 & 0.1 & 0.02 & 0.19 & $\mathrm{Ha}$ & \\
\hline .16 & 0.36 & -0.4 & -0.41 & 0.3 & -0.32 & 0.08 & 0.57 & 0.15 & -0.19 & \\
\hline
\end{tabular}

(B)

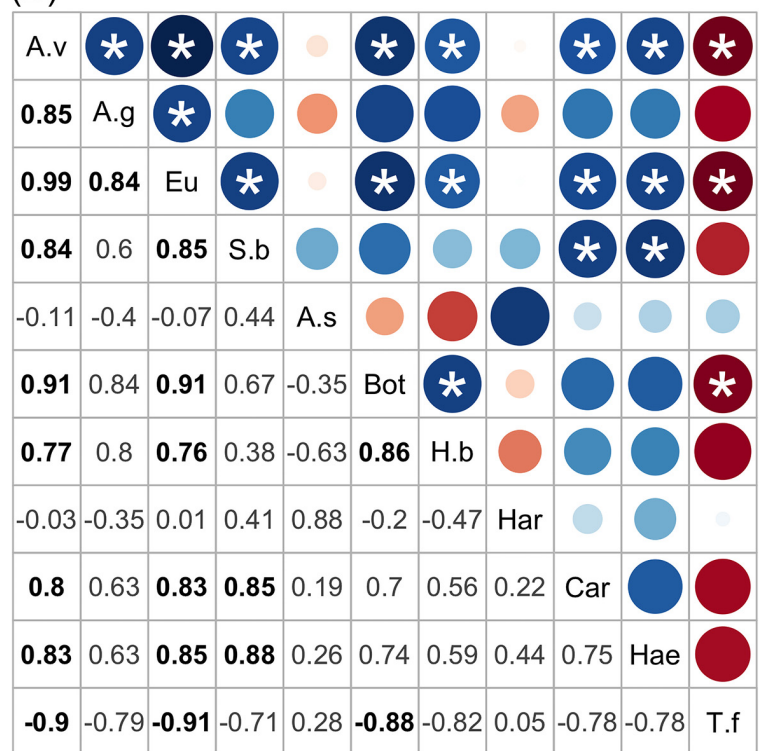

(C)

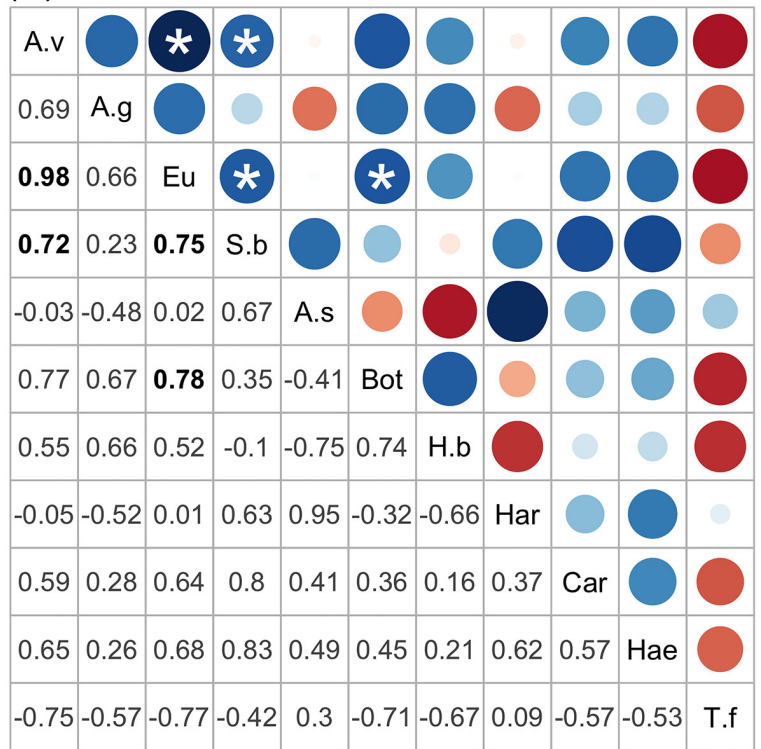

FIG. 2. Graphical representation of environmental (a), residual (b), and partial (c) correlation matrices estimated by the joint species distribution model (JSDM). Environmental correlations reflect covariation in species' abundance linked to habitat variability, whereas residual correlations represent the covariation that remains after controlling for the effects of habitat, putatively evidencing species interactions. Partial correlations, obtained by inversion of the residual correlation matrix, control for indirect effects and are thus more reliable indicators of direct pairwise interactions. The size and shading of circles in the upper triangle conveys the strength and direction of correlations, with asterisks denoting significant relationships (i.e., $95 \%$ HPD intervals did not encompass zero). Correlation coefficients are displayed in the lower triangle, with significant relationships bolded. Taxa are identified on the diagonal, abbreviated as follows: A.v $=$ Albula vulpes, A.g $=$ Albula goreensis, A.s $=$ Atherinomorus stipes, Bot $=$ Bothus spp., Car $=$ Caran $x$ spp., Eu $=$ Eucinostomus spp., Hae $=$ Haemulon spp., Har $=$ Harengula spp., H.b $=$ Halichoeres bivittatus, S.b $=$ Sphyraena barracuda, T.f $=$ Trachinotus falcatus .

between $A$. vulpes and Eucinostomus spp. Likewise, Bothus spp. and $S$. barracuda both displayed comparably strong positive correlations with eucinostomids. Following expectation, save for a somewhat weaker positive correlation between $A$. vulpes and $S$. barracuda, the relationships of these two species with other taxa were no longer significant after controlling for their close correspondence with eucinostomids. Despite significant 
residual correlations and high rates of co-occurrence between several other fishes and Eucinostomus spp. (such as Haemulon spp. or grunts, and Albula goreensis), partial correlations for these taxa were not significantly different from zero.

The influence of taxa in pairwise relationships was often heavily skewed or one-sided for both residual and partial correlations (Appendix S3: Table S5). For example, in the case of the strongest estimated residual correlation, the effect of Eucinostomus spp. on A. vulpes was nearly 10 times the reciprocal effect of $A$. vulpes on eucinostomids. This pattern was consistent across all taxa that shared significant residual correlations with Eucinostomus spp., with eucinostomids exerting a much larger effect than their counterparts in any given species pair. Asymmetric relationships were also apparent in the case of other taxa such as $S$. barracuda, but to a considerably lesser degree. Therefore, despite several fishes sharing similar numbers of significant residual correlations of generally comparable strength, the total estimated influence of distinct taxa on community structure (as measured by $n w D_{\text {out }}$ ) varied greatly, spanning several orders of magnitude (Fig. 3). Eucinostomus spp. exerted a disproportionately large overall effect in the residual correlation network (Fig. 4a), roughly four times that of the next most influential species, S. barracuda, and substantially greater than (about twice) that of all other significantly correlated species combined. Analogous patterns emerged in the partial correlation network (Fig. 4b), with Eucinostomus spp. exhibiting by far the largest net effect on assemblage structure, on the order of four times that of S. barracuda and approximately 2.5 times that of the other three taxa combined.

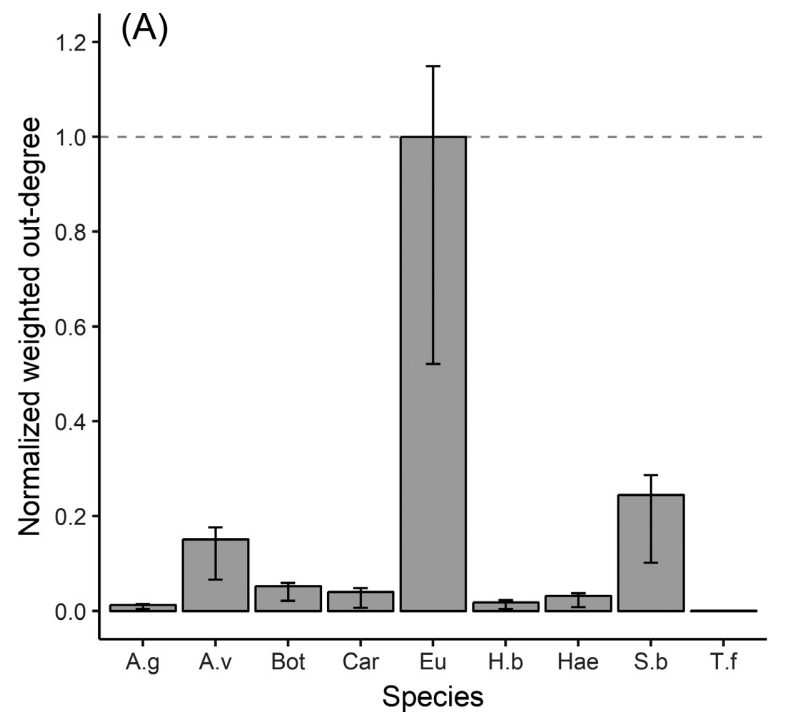

\section{Discussion}

This study is, to the authors' best knowledge, among few to examine the social structure of juvenile fish assemblages in wild communities while accounting explicitly for the confounding effects of habitat filtering, accomplishing this through the application of an innovative statistical approach. In so doing, this work advances our understanding of the factors that act to shape fish assemblages during a pivotal and often enigmatic developmental stage, revealing the central but underrecognized importance of positive heterospecific associations. Simultaneously, this research presents a rare empirical examination of heretofore mainly theoretical predictions about the influence of social information on the organization of mixed-species groups, suggesting that ontogeny may play an important role in mediating its significance.

The patterns of association elucidated by our analysis are in close agreement with those theorized to arise in the presence of heterospecific information use (Seppänen et al. 2007, Goodale et al. 2010, Gil et al. 2017), displaying a marked bias towards nonrandom positive associations that connote commensal or mutualistic interactions. Following predictions, associations were mostly limited to ecologically similar taxa, occurring almost exclusively among species of the same functional group (benthivores). Furthermore, most affiliations occurred between fishes whose adult life stages were characterized by sharply contrasting body sizes, trophic positions, and patterns of habitat use, and therefore by neutral, heavily asymmetric, or predator-prey relationships. Finally, there were pronounced differences in the number and strength of positive associations among

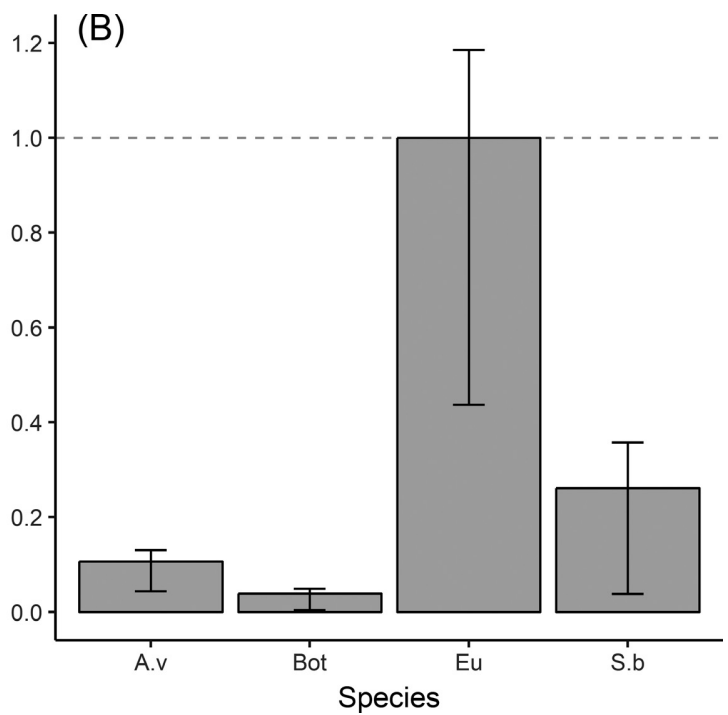

FIG. 3. Bar plots depicting the relative influence of distinct taxa on overall assemblage structure, as measured by their normalized weighted out-degree $\left(\mathrm{nwD}_{\text {out }}\right)$ in the residual (a) and partial (b) compositional networks, as depicted in Fig. 4. Error bars represent uncertainty incorporated through the $95 \%$ highest posterior density intervals of pairwise correlations. Taxa are identified using the abbreviations described in Fig. 2, and those with no significant correlations have been omitted. 

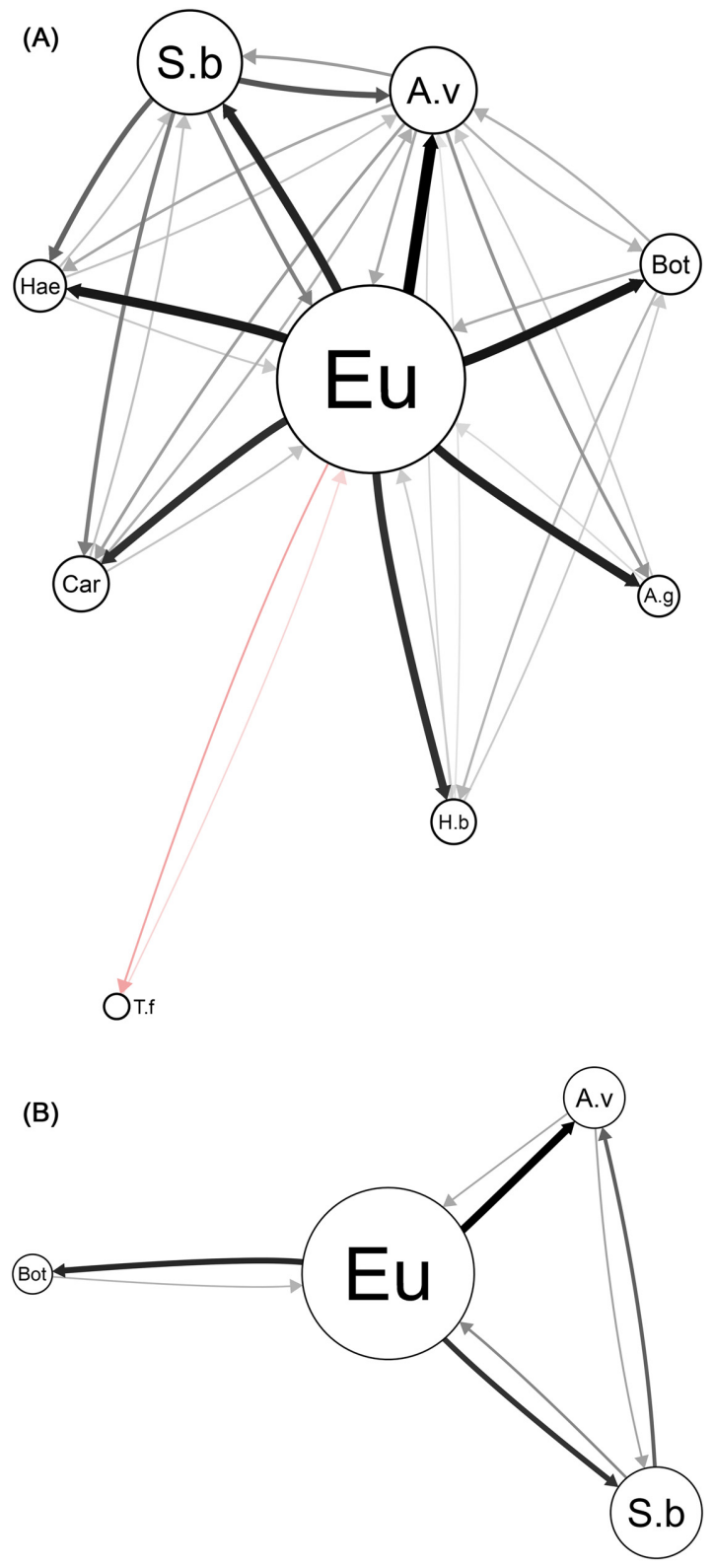

FIG. 4. Compositional networks depicting assemblage structure inferred from asymmetrically weighted residual (a) and partial (b) correlations estimated by the joint species distribution model (JSDM). Nodes (i.e., circles) represent taxa, and edges (i.e., arrows) between nodes signify positive (black) or negative (red) pairwise relationships. The widths and opacities of outgoing edges are scaled by association strengths, reflecting the influence of their originating node (i.e., taxon) on their terminating node. Node sizes are scaled by the square root of the taxon's normalized weighted out-degree $\left(\mathrm{nwD}_{\text {out }}\right)$, approximating their overall influence on assemblage structure. Taxa are identified using the abbreviations described in Fig. 2, and those with no significant correlations have been omitted.

fishes, with assemblage structure affected inordinately by a single taxon (Eucinostomus spp.) whose traits imply an exceptional capacity for information production (as discussed below). Collectively, these findings offer strong support for the hypotheses that (1) interspecific information transfer, and its consequent effects on fitness, were key factors driving the high rates of heterospecific grouping observed; and (2) the increased exploitation of information across species likely arose due to increased niche overlap linked to body size congruency in early ontogenetic stages.

Although a common practice, inferring interactions from compositional data can be problematic, and thus we took extensive measures to eliminate or mitigate possible sources of Type I error. For example, some individuals captured in seine hauls may have represented fractions of, or multiple and distinct fish shoals so that a proportion of joint occurrences were likely coincidental, resulting from species sharing habitats but not necessarily interacting. In such a case, the positive correlations of several fishes with Eucinostomus spp. might be interpreted simply to reflect this taxon's ubiquitous nature. However, we controlled for this contingency by explicitly modeling and isolating correlation induced by such chance events (Fig. 2a), preventing it from inflating the significance of relationships between species whose overlapping habitat requirements yielded a high probability of co-occurrence. Likewise, by accounting for covariance in species abundance linked to unmeasured habitat variability, the inclusion of random station effects further reduced the likelihood of identifying false relationships. Despite this, it is still conceivable that unrecognized habitat differences independent of station could have influenced latent variables, though many such factors (e.g., benthic prey densities) were likely correlated with measured covariates (Brind'Amour et al. 2005, Boström et al. 2006). Finally, partial correlations served yet again to filter out spurious or indirect relationships so that, compared to those obtained by traditional nullmodel or purely probabilistic methods (Gotelli and Ulrich 2010, Veech and Araújo 2014), the pairwise associations we infer here represent a conservative estimation.

Although our statistical approach to identifying nonrandom associations required no implicit assumptions about shoal membership or the spatiotemporal scales of interactions, the exchange of information to which we accredit these relationships is nevertheless conditional upon individuals occurring within close proximity in time and space (Seppänen et al. 2007)—namely, in a mixed-species shoal. Considering the extensive suite of environmental factors that we controlled for and the relatively small area sampled by seine hauls, there seems little doubt that the relationships inferred from partial correlations (and to a lesser degree residual correlations) are indeed reflective of species interactions occurring at local scales (Golding et al. 2015, Ovaskainen et al. 2017). This presumption is validated by in situ behavioral observations obtained from remote underwater video surveys, which not only produced incontrovertible evidence of $A$. vulpes and $S$. barracuda juveniles commingled among Eucinostomus spp. shoals, but also 
revealed organizational patterns paralleling those inferred from the JSDM (Appendix S4 and Video S1). In fact, related behavioral experiments demonstrate conclusively that $A$. vulpes juveniles elect to join Eucinostomus spp. shoals over those of conspecifics and other heterospecifics (Szekeres et al., unpublished manuscript).

Nearby individuals whose actions convey information on the threat posed by shared predators almost inexorably serve as risk dilutors as well, and consequently intrinsic numerical and information-related factors often work in tandem to reduce an individual's risk of predation (Dehn 1990, Rieucau et al. 2012), particularly when group sizes are large (Beauchamp 2017). As such, one might assert that the mixed-species groups described here may be just as readily explained by the intrinsic numerical benefits of joining others; however, this hypothesis is not consistent with the organizational patterns we detected. Given their distinctive phenotypes and invariably low abundance compared to eucinostomids (Table 2), the conspicuity of associate taxa (i.e., $A$. vulpes, S. barracuda, and Bothus spp.) could draw the attention of predators, largely negating the advantages of risk dilution (i.e., "the oddity effect," Wolf 1985, Landeau and Terborgh 1986), and instead favoring conspecifics as shoal partners if numerical benefits were the main drivers of association (Mathis and Chivers 2003, Rodgers et al. 2011). Moreover, if mixed-species shoal participation served mainly to permit larger group sizes among fishes for whom the availability of conspecifics was limited (Ogden and Ehrlich 1977), those most closely associating with heterospecifics should be among the rarer or less frequently encountered taxa; yet conversely, these were among the more commonly occurring or abundant fishes.

Likewise, neighboring individuals whose foraging activities reduce uncertainty about mutually exploited resources are also likely to be competitors, inflicting penalties that can offset grouping benefits (Seppänen et al. 2007). Therefore, the positive fitness effects of social information tend to be greatest when resources are abundant and/or the costs of competition are low (Gil et al. 2017). The benthic infauna and epifauna upon which most of the closely associated fishes feed occur in very high densities (Alongi 1989, Dittmann 2002) and are thought to be only modestly impacted by fish predation (Henry and Jenkins 1995), suggesting that prey resources are typically not limiting in such systems (DeFelice and Parrish 2003, De Raedemaecker et al. 2011). Moreover, despite sharing superficial similarities in foraging mode, the most strongly affiliated benthivores displayed clear differences in functional morphology and corresponding prey-capture strategies indicative of considerable niche complementarity, as has been described among other soft-bottom benthivores (Sazima 1986, Labropoulou and Eleftheriou 1997, Labropoulou and Papadopoulou-Smith 1999). Accordingly, the likelihood of strong resource competition between associating fishes appears low, a notion further supported by the absence of discernable agonistic interactions in remote video surveys (Appendix S4).

In light of the above considerations, we conclude that while likely acting in conjunction with intrinsic numerical mechanisms (or more complex iterations of them; e.g., Tosh et al. 2007, Rodgers et al. 2013), interspecific information transfer provides the most plausible explanation for the organization of observed assemblages. This assessment aligns with studies in terrestrial systems, which have determined that, setting aside food-related gains, the antipredator benefits of collective detection were the principal driver of grouping behavior (Schmitt et al. 2014, van der Marel et al. 2019). Potential support for this inference may also be found in the theoretical models of Gil et al. (2017), which despite neglecting the penalties incurred through phenotypic oddity, showed that the proportional fitness contributions of social information can rival or even exceed those of intrinsic benefits in many situations. Moreover, because the increased probability of predator attack due to oddity directly counteracts the advantages of risk dilution but has little effect on the benefits of social information, the relative importance of information should be all the greater in the presence of an oddity effect.

\section{Ontogenetic constraints on body size affect the relevance of information across taxa}

Of the ways that ontogenically imposed body size limitation may enhance the fitness benefits obtained by mixed-species group participation in early life, the most universally applicable to the fishes studied here may be via its convergent effects on predation risk (Anderson 1988, Sogard 1997), which arise because of strong metabolic and size-dependent constraints on trophic interactions (Christensen 1996, Scharf et al. 2000). Adult body sizes range roughly an order of magnitude among these species, implying large asymmetries in their respective vulnerabilities to a given predator. For example, the threat posed by a 500-mm FL young-of-year lemon shark (Negaprion brevirostris) is logically much greater for a typical Eucinostomus spp. adult $(\mathrm{FL} \approx 125 \mathrm{~mm}$ ) than for an $A$. vulpes adult (FL $\approx 450 \mathrm{~mm}$ ). Because of this incongruity, social cues conveying the threat perceived by adults of one taxon may constitute an over- or underestimation of risk for the other, precipitating negative fitness consequences in the form of unnecessary energetic expenditures, lost foraging opportunities, or predation mortality (Lima 1998, Searcy and Nowicki 2005). In contrast, the same predator should pose a more symmetrical threat to comparably sized juveniles of these two fishes, reducing the potential for such incompatibilities and their associated costs.

It is worth noting that although others have posited that the heightened risk of predation concomitant with small body size may drive increased grouping propensity 
among small individuals (Thiollay and Jullien 1998, Sridhar et al. 2009), the principal mechanism we propose to be at work here is fundamentally different. We suggest that it is not the elevated absolute level of predation risk faced by juveniles per se, but instead the greater homogeneity in vulnerability experienced across species that acts primarily to amplify the adaptive significance of heterospecific grouping during this period of ontogeny, as body size uniformity yields greater overlap in shared predators (i.e., convergence in prey guild membership) and consequently increases the mutual pertinence of threat-related social cues among various taxa. Precedents for this idea can be found in mixed-species groups of birds and mammals, where experimental studies have shown that the strength of a species' response to heterospecific alarm cues is correlated with body size similarity (Hua et al. 2016, Meise et al. 2018), likely explaining the positive relationship between size homogeneity and association strength that has been documented in avian flocks (Sridhar et al. 2012).

Developmental constraints on body size can also change the basic nature of interspecific relationships, so that taxa typically regarded as predator and prey may in fact occupy similar trophic positions and prey guilds as juveniles (Werner and Gilliam 1984, Olson et al. 1995). Ontogeny can thus have direct repercussions not just for the relevance of information between individuals but for the way in which it is exploited, determining whether heterospecific cues elicit a defensive (i.e., antipredator) or aggressive (i.e., feeding) response (Brown et al. 2001, Elvidge et al. 2010). Such a phenomenon may be exemplified in the relationship between $S$. barracuda and Eucinostomus spp.; although essentially absent from the diet of $S$. barracuda in the size classes we considered, eucinostomids are an important food source for larger juveniles and subadults (De Sylva 1963, Hammerschlag et al. 2010). Hence, juvenile $S$. barracuda appear to undergo an ontogenetic shift in their response to the social cues of Eucinostomus spp., using them to identify low-risk areas in which to forage or to evade predators as early juveniles, but mean while exploiting the same cues to preys upon their originators later in life, in a pattern not unlike that described for Centropomus spp., another shallow-water piscivore that associates closely with eucinostomids (Sazima 2002).

The functional group-specific nature of associations, which occurred predominantly among benthic invertivores, implies that access to food-related social information also acted in part to motivate the observed relationships, a notion made all the more likely by the unique prey-detection abilities of Eucinostomus spp. (discussed in detail below). Indeed, theoretical models indicate that in most contexts the fitness gains accrued through socially acquired information on resources outweigh those obtained from risk-related information, even when trophic niche overlap is relatively low (Gil et al. 2017). Thus, despite their considerable niche complementarity, the associated benthivores may have obtained valuable knowledge about the distribution of trophic resources by monitoring the foraging activities of heterospecifics (Valone and Templeton 2002), possibly through patch-scale area copying or local enhancement processes (Pitcher and House 1987, Ryer and Olla 1992). Moreover, the pervasiveness of facilitative interactions among intertidal soft-sediment invertebrates promotes strong positive covariation in their abundances (Thrush et al. 1992, Dittmann 1996, Thrush et al. 2008), suggesting that social information pertaining to food may have been profitable even between fishes exploiting altogether distinct prey taxa.

Accordingly, the same mechanisms that produce convergence in prey guild membership among juvenile heterospecifics should also give rise to increased congruency in predator guild association, as disparate species subject to similar size-related constraints on resource use are forced to occupy narrowed and overlapping trophic niches (Scharf et al. 2000, Woodward and Hildrew 2002). In fact, although several of the taxa exhibiting significant positive correlations are chiefly piscivorous as adults (e.g., Bothus spp., Caranx spp., and S. barracuda), all but a single species (S. barracuda) can be classified principally as invertivores during the developmental period we considered (Randall 1967, Layman and Silliman 2002). Whereas the feeding advantages to be gained by the piscivorous $S$. barracuda are less evident, early juveniles often consume small epibenthic fishes such as gobiids and cyprinodonts (De Sylva 1963, Schmidt 1989) and thus may benefit by preying upon these taxa as they are attracted to (or flushed by) the activities of foraging eucinostomids, as has also been documented for Centropomus spp. (Sazima 2002).

\section{Role of information-producing species}

The strong association with Eucinostomus spp. shared by a variety of fishes suggests that this taxon acted in a nuclear role, a phenomenon that can be ascribed to their embodiment of several key traits, which together imply a singular potential to detect and produce information on both resources and predators reliably; qualities that are consistently offered to explain the attractiveness of nuclear or sentinel species across diverse taxa and ecosystems.

Eucinostomus spp. possess specialized sensory physiology comprising a direct physical connection between the inner ear, swim bladder, and ventrally oriented anal fin spines, providing remarkably high otic sensitivity that is used to discern, acoustically, the location of cryptic or buried prey within benthic substrates (Green 1971, Parmentier et al. 2011). Not only does this adaptation impart a seemingly unmatched ability to locate otherwise imperceptible resources, but it permits Eucinostomus spp. to maintain an upright posture conducive to antipredator awareness while concurrently searching for prey, circumventing the myopic focus on benthic substrates that makes visually oriented benthivores particularly vulnerable to predation (Krause and Godin 1996). 
These attributes probably account for the extended pauses in locomotion that typify the distinctive intermittent or saltatory foraging strategy of eucinostomids (Sazima 2002, Parmentier et al. 2011), a behavioral trait that in itself implies a high capacity for antipredator vigilance (McAdam and Kramer 1998, Kramer and McLaughlin 2001).

Among the more common constituents of shallow subtropical systems, Eucinostomus spp. are highly social, foraging in large conspecific or congeneric shoals over an expansive array of habitats (Kerschner et al. 1985, Serafy et al. 2003, Newman et al. 2007), basic aspects of their ecology that may further magnify the efficacy of this taxon as an informant. Perhaps the most oft-cited trait of nuclear species (Goodale and Beauchamp 2010), the intraspecific gregariousness of eucinostomids serves not only to increase collective detection ability and the accuracy of decisions, but also to amplify any resultant cues, increasing the likelihood they will be observed by others (Goodale et al. 2010, Ward et al. 2011). Moreover, their generalist nature implies that any information produced by eucinostomids is both relevant and accessible to a diversified heterospecific audience (Goodale et al. 2010). As such, the presence, density, or activity of Eucinostomus spp. shoals may simultaneously convey both risk and resource-related information, indicating relatively productive and low-risk areas in which to feed. In this way, eucinostomids may function as "keystone informants" for more vulnerable benthivores that are inefficient at locating concealed prey and that may also exploit the vigilance of others to reduce their own risk of predation (Thiollay and Jullien 1998, Sridhar et al. 2009).

\section{Broader relevance}

The outcome of this research can be seen as providing empirical support for recent theoretical works on the role of information transfer in shaping animal groups (Seppänen et al. 2007, Gil et al. 2017), highlighting the extensive influence that "informant" species may exert on community assemblage (Hetrick and Sieving 2012, Magrath et al. 2015). The predominance of positive interactions uncovered here contradicts several previous studies, which have found that competition, principally for structural predation refugia, is among the most influential interactions organizing juvenile fish communities in tropical marine waters (Hixon and Beets 1993, Hixon and Jones 2005). This discrepancy may be explained by fundamental differences in the nature of the benthic habitats we studied; compared to the structurally complex coral reefs where most prior works were conducted, the shallow littoral zones we surveyed were more open and topographically homogenous. Thus, the relative lack of fine-scale antipredator refuge in our system may have prompted a greater reliance on social mechanisms to avoid predation, in keeping with other empirical and experimental observations (Auster and Lindholm 2008, Orpwood et al. 2008).
Our findings also suggest that ontogenetic similarity may supersede phylogenetic relatedness in determining the relevance of information in size-or-stage-structured communities, offering a parsimonious explanation for the high incidence of heterospecific association among juvenile fishes. Although it is well-recognized that ontogenetic niche shifts can fundamentally alter interspecific relationships, turning competitors into predator and prey and vice versa (i.e., "intraguild predation"; Polis and Holt 1992, Woodward and Hildrew 2002), our work implies that developmental shifts can likewise effectuate mutualistic or at least commensal relationships among competitors ("intraguild mutualism"; Crowley and Cox 2011), and even between predators and their prey. In the absence of stage-based considerations, socially acquired information and the positive relationships that arise through its use can have complex and widespread implications for population-level and community dynamics (Gross 2008, Assaneo et al. 2013, Gil et al. 2018), facilitating coexistence but also introducing theoretical instabilities. Ontogenetic shifts in the exploitation of information as described here have the potential to induce stage-dependent demographic coupling and feedbacks that may further complicate these dynamics, reinforcing the need to integrate ontogeny and demography when modeling communities (De Roos et al. 2003, Rudolf and Rasmussen 2013b).

\section{ACKnowledgments}

The authors thank L. Griffin, J. Lewis, and B. Sims for their help with data collection, as well as A. Shultz, K. Murchie, E. Wallace, and D. Philipp for their support throughout the process of completing this work. We are likewise grateful to A. Wilson, A. Harborne, and M. Mitchell for their input on various iterations of this manuscript. The final manuscript also benefited from the constructive input of M. Gil and a second, anonymous reviewer. Our work was made possible by funding from the Bonefish \& Tarpon Trust, UMass Intercampus Marine Science Graduate Program, and the Department of Environmental Conservation at the University of Massachusetts Amherst. A. Danylchuk was supported the National Institute of Food \& Agriculture, U.S. Department of Agriculture, the Massachusetts Agricultural Experiment Station, and Department of Environmental Conservation and is also a Bonefish \& Tarpon Trust Research Fellow. All fish sampling for this study was approved by the University of Massachusetts Amherst Institutional Animal Care and Use Committee (protocol 2010-0005).

\section{Literature Cited}

Alongi, D. M. 1989. Ecology of tropical soft-bottom benthos: a review with emphasis on emerging concepts. Revista de Biologia Tropical 37:85-100.

Anderson, J. T. 1988. A review of size dependent survival during pre-recruit stages of fishes in relation to recruitment. Journal of Northwest Atlantic Fishery Science 8:55-66.

Araújo, M. B., and M. Luoto. 2007. The importance of biotic interactions for modelling species distributions under climate change. Global Ecology and Biogeography 16:743-753.

Araújo, M. B., A. Rozenfeld, C. Rahbek, and P. A. Marquet. 2011. Using species co-occurrence networks to assess the impacts of climate change. Ecography 34:897-908. 
Assaneo, F., R. M. Coutinho, Y. Lin, C. Mantilla, and F. Lutscher. 2013. Dynamics and coexistence in a system with intraguild mutualism. Ecological Complexity 14:64-74.

Auster, P., and J. Lindholm.2008. Variation in social foraging by fishes across a coral reef landscape. Pages 286-290 in Proceedings of the 11th International Coral Reef Symposium.

Basset, A. 1995. Body size-related coexistence: an approach through allometric constraints on home-range use. Ecology 76:1027-1035.

Beauchamp, G. 2017. Disentangling the various mechanisms that account for the decline in vigilance with group size. Behavioural Processes 136:59-63.

Bertness, M. D., and R. Callaway. 1994. Positive interactions in communities. Trends in Ecology \& Evolution 9:191-193.

Blanchet, S., J. Clobert, and E. Danchin. 2010. The role of public information in ecology and conservation: an emphasis on inadvertent social information. Annals of the New York Academy of Sciences 1195:149-168.

Boström, C., K. O'Brien, C. Roos, and J. Ekebom. 2006. Environmental variables explaining structural and functional diversity of seagrass macrofauna in an archipelago landscape. Journal of Experimental Marine Biology and Ecology 335:52-73.

Brind'Amour, A., D. Boisclair, P. Legendre, and D. Borcard. 2005. Multiscale spatial distribution of a littoral fish community in relation to environmental variables. Limnology and Oceanography 50:465-479.

Brooks, S. P., and A. Gelman. 1998. General methods for monitoring convergence of iterative simulations. Journal of Computational and Graphical Statistics 7:434-455.

Brown, G. E., V. J. LeBlanc, and L. E. Porter. 2001. Ontogenetic changes in the response of largemouth bass (Micropterus salmoides, Centrarchidae, Perciformes) to heterospecific alarm pheromones. Ethology 107:401-414.

Bruno, J. F., J. J. Stachowicz, and M. D. Bertness. 2003. Inclusion of facilitation into ecological theory. Trends in Ecology \& Evolution 18:119-125.

Buckley, N. J.. 1996. Food finding and the influence of information, local enhancement, and communal roosting on foraging success of North American vultures. The Auk 113:473-488.

Christensen, B. 1996. Predator foraging capabilities and prey antipredator behaviours: pre- versus postcapture constraints on size-dependent predator-prey interactions. Oikos 76:368-380.

Coolen, I., Y. van Bergen, R. L. Day, and K. N. Laland. 2003. Species difference in adaptive use of public information in sticklebacks. Proceedings of the Royal Society of London B 270:2413-2419.

Crowley, P. H., and J. J. Cox. 2011. Intraguild mutualism. Trends in Ecology \& Evolution 26:627-633.

Dall, S. R., L. A. Giraldeau, O. Olsson, J. M. McNamara, and D. W. Stephens. 2005. Information and its use by animals in evolutionary ecology. Trends in Ecology \& Evolution 20:187193.

Dayan, T., and D. Simberloff. 2005. Ecological and communitywide character displacement: the next generation. Ecology Letters 8:875-894.

De Raedemaecker, F., I. O'Connor, D. Brophy, and A. Black. 2011. Macrobenthic prey availability and the potential for food competition between 0 year group Pleuronectes platessa and Limanda limanda. Journal of Fish Biology 79:1918-1939.

De Roos, A. M., L. Persson, and E. McCauley. 2003. The influence of size-dependent life-history traits on the structure and dynamics of populations and communities. Ecology Letters 6:473-487.

De Sylva, D. P. 1963. Systematics and life history of the great barracuda, Sphyraena barracuda (Walbaum). Pages 1-179 in Studies in tropical oceanography. University of Miami.
DeFelice, R. C., and J. D. Parrish. 2003. Importance of benthic prey for fishes in coral reef-associated sediments. Pacific Science 57:359-384.

Dehn, M. M.. 1990. Vigilance for predators: detection and dilution effects. Behavioral Ecology and Sociobiology 26:337342 .

Dittmann, S.. 1996. Effects of macrobenthic burrows on infaunal communities in tropical tidal flats. Marine Ecology Progress Series 134:119-130.

Dittmann, S. 2002. Benthic fauna in tropical tidal flats-a comparative perspective. Wetlands Ecology and Management 10:189-195.

Elvidge, C. K., I. W. Ramnarine, J. G. Godin, and G. E. Brown. 2010. Size-mediated response to public cues of predation risk in a tropical stream fish. Journal of Fish Biology 77:1632-1644.

Epskamp, S., A. O. Cramer, L. J. Waldorp, V. D. Schmittmann, and D. Borsboom. 2012. qgraph: Network visualizations of relationships in psychometric data. Journal of Statistical Software 48:1-18.

Foster, W. A., and J. E. Treherne. 1981. Evidence for the dilution effect in the selfish herd from fish predation on a marine insect. Nature 293:466.

Gelman, A., and D. B. Rubin. 1992. Inference from iterative simulation using multiple sequences. Statistical Science $7: 457-472$.

Geweke, J.. 1992. Evaluating the accuracy of sampling-based approaches to the calculations of posterior moments. Bayesian Statistics 4:641-649.

Gil, M. A., and A. M. Hein. 2017. Social interactions among grazing reef fish drive material flux in a coral reef ecosystem. Proceedings of the National Academy of Sciences 114:4703-4708.

Gil, M. A., Z. Emberts, H. Jones, and C. M. St Mary. 2017. Social information on fear and food drives animal grouping and fitness. American Naturalist 189:227-241.

Gil, M. A., A. M. Hein, O. Spiegel, M. L. Baskett, and A. Sih. 2018. Social information links individual behavior to population and community dynamics. Trends in Ecology \& Evolution 33:535-548.

Giraldeau, L. A., T. J. Valone, and J. J. Templeton. 2002. Potential disadvantages of using socially acquired information. Philosophical Transactions of the Royal Society of London B 357:1559-1566.

Golding, N., M. A. Nunn, and B. V. Purse. 2015. Identifying biotic interactions which drive the spatial distribution of a mosquito community. Parasites \& Vectors 8:367.

Goodale, E., and G. Beauchamp. 2010. The relationship between leadership and gregariousness in mixed-species bird flocks. Journal of Avian Biology 41:99-103.

Goodale, E., and S. W. Kotagama. 2005. Testing the roles of species in mixed-species bird flocks of a Sri Lankan rain forest. Journal of Tropical Ecology 21:669-676.

Goodale, E., and S. W. Kotagama. 2008. Response to conspecific and heterospecific alarm calls in mixed-species bird flocks of a Sri Lankan rainforest. Behavioral Ecology 19:887-894.

Goodale, E., G. Beauchamp, R. D. Magrath, J. C. Nieh, and G. D. Ruxton. 2010. Interspecific information transfer influences animal community structure. Trends in Ecology \& Evolution 25:354-361.

Goodale, E., G. Beauchamp, and G. D. Ruxton.2017. Mixedspecies groups of animals: behavior, community structure, and conservation. Academic Press, London, UK.

Gotelli, N. J., and D. J. McCabe. 2002. Species co-occurrence: A meta-analysis of J. M. Diamond's assembly rules model. Ecology 83:2091-2096.

Gotelli, N. J., and W. Ulrich. 2010. The empirical Bayes approach as a tool to identify non-random species associations. Oecologia 162:463-477. 
Gravel, D., T. Poisot, C. Albouy, L. Velez, D. Mouillot, and R. Freckleton. 2013. Inferring food web structure from predator-prey body size relationships. Methods in Ecology and Evolution 4:1083-1090.

Green, J. M. 1971. Studies on the swim bladders of Eucinostomus gula and E. argenteus (Pisces: Gerridae). Bulletin of Marine Science 21:567-590.

Gross, K. 2008. Positive interactions among competitors can produce species-rich communities. Ecology Letters 11:929936.

Gust, N., J. Choat, and J. Ackerman. 2002. Demographic plasticity in tropical reef fishes. Marine Biology 140:1039-1051.

Haak, C. R., G. W. Cowles, and A. J. Danylchuk. 2019. Wave and tide-driven flow act on multiple scales to shape the distribution of a juvenile fish (Albula vulpes) in shallow nearshore habitats. Limnology and Oceanography 64:597-615.

Hamilton, W. D. 1971. Geometry for the selfish herd. Journal of Theoretical Biology 31:295-311.

Hammerschlag, N., D. Ovando, and J. E. Serafy. 2010. Seasonal diet and feeding habits of juvenile fishes foraging along a subtropical marine ecotone. Aquatic Biology 9:279-290.

Harborne, A. R., P. J. Mumby, C. V. Kappel, C. P. Dahlgren, F Micheli, K. E. Holmes, and D. R. Brumbaugh. 2008. Tropical coastal habitats as surrogates of fish community structure, grazing, and fisheries value. Ecological Applications 18:1689-1701.

Harris, D. J. 2016. Inferring species interactions from co-occurrence data with Markov networks. Ecology 97:3308-3314.

Hein, A. M., M. A. Gil, C. R. Twomey, I. D. Couzin, and S. A. Levin. 2018. Conserved behavioral circuits govern high-speed decision-making in wild fish shoals. Proceedings of the National Academy of Sciences 115:12224.

Henry, B. A., and G. P. Jenkins. 1995. The impact of predation by the girdled goby, Nesogobius sp. 1, on abundances of meiofauna and small macrofauna. Journal of Experimental Marine Biology and Ecology 191:223-238.

Hetrick, S. A., and K. E. Sieving. 2012. Antipredator calls of tufted titmice and interspecific transfer of encoded threat information. Behavioral Ecology 23:83-92.

Hildrew, A. G., D. G. Raffaelli, and R. Edmonds-Brown. 2007. Body size: the structure and function of aquatic ecosystems. Cambridge University Press, Cambridge, UK

Hixon, M. A., and J. P. Beets. 1993. Predation, prey refuges, and the structure of coral-reef fish assemblages. Ecological Monographs 63:77-101.

Hixon, M. A., and G. P. Jones. 2005. Competition, predation, and density-dependent mortality in demersal marine fishes. Ecology 86:2847-2859.

Hua, F., D. L. Yong, M. N. Janra, L. M. Fitri, D. Prawiradilaga, and K. E. Sieving. 2016. Functional traits determine heterospecific use of risk-related social information in forest birds of tropical South-East Asia. Ecology and Evolution 6:8485-8494.

Hui, F. K. C.. 2016. boral-Bayesian ordination and regression analysis of multivariate abundance data inr. Methods in Ecology and Evolution 7:744-750.

Hui, F. K. C., S. Taskinen, S. Pledger, S. D. Foster, D. I. Warton, and R. B. O'Hara. 2015. Model-based approaches to unconstrained ordination. Methods in Ecology and Evolution 6:399-411.

Karplus, I., B. Zion, L. Rosenfeld, Y. Grinshpun, T. Slosman, Z. Goshen, and A. Barki. 2007. Social facilitation of learning in mixed-species schools of common carp Cyprinus carpio $\mathrm{L}$. and Nile tilapia Oreochromis niloticus (L.). Journal of Fish Biology 71:1023-1034

Keddy, P. A.. 1992. Assembly and response rules: two goals for predictive community ecology. Journal of Vegetation Science 3:157-164.
Kerschner, B. A., M. S. Peterson, and R. Grant Gilmore. 1985. Ecotopic and ontogenetic trophic variation in mojarras (Pisces: Gerreidae). Estuaries 8:311-322.

Kissling, W. D., et al. 2012. Towards novel approaches to modelling biotic interactions in multispecies assemblages at large spatial extents. Journal of Biogeography 39:2163-2178.

Kohda, M., J. Y. Shibata, S. Awata, D. Gomagano, T. Takeyama, M. Hori, and D. Heg. 2008. Niche differentiation depends on body size in a cichlid fish: a model system of a community structured according to size regularities. Journal of Animal Ecology 77:859-868.

Kramer, D. L., and R. L. McLaughlin. 2001. The behavioral ecology of intermittent locomotion. American Zoologist 41:137-153.

Krause, J., and J.-G. J. Godin. 1996. Influence of prey foraging posture on flight behavior and predation risk: predators take advantage of unwary prey. Behavioral Ecology 7:264-271.

Krause, J., and G. D. Ruxton. 2002. Living in groups. Oxford University Press, Oxford, UK.

Labropoulou, M., and A. Eleftheriou. 1997. The foraging ecology of two pairs of congeneric demersal fish species: importance of morphological characteristics in prey selection. Journal of Fish Biology 50:324-340.

Labropoulou, M., and K. N. Papadopoulou-Smith. 1999. Foraging behaviour patterns of four sympatric demersal fishes. Estuarine, Coastal and Shelf Science 49:99-108.

Landeau, L., and J. Terborgh. 1986. Oddity and the 'confusion effect' in predation. Animal Behaviour 34:1372-1380.

Layman, C. A., and B. R. Silliman. 2002. Preliminary survey and diet analysis of juvenile fishes of an estuarine creek on Andros Island, Bahamas. Bulletin of Marine Science 70:199-210.

Leyequién, E., W. F. de Boer, and A. Cleef. 2007. Influence of body size on coexistence of bird species. Ecological Research 22:735-741

Lima, S. L. 1998. Nonlethal effects in the ecology of predatorprey interactions. BioScience 48:25-34.

Lukoschek, V., and M. I. McCormick.2000. A review of multispecies foraging associations in fishes and their ecological significance. Pages 467-474 in Proceedings of the 9th International Coral Reef Symposium. Ministry of Environment, the Indonesian Institute of Sciences and the International Society for Reef Studies.

Magrath, R. D., T. M. Haff, P. M. Fallow, and A. N. Radford. 2015. Eavesdropping on heterospecific alarm calls: from mechanisms to consequences. Biological Reviews of the Cambridge Philosophical Society 90:560-586.

van der Marel, A., M. López-Darias, and J. M. Waterman. 2019. Group-enhanced predator detection and quality of vigilance in a social ground squirrel. Animal Behaviour 151:4352 .

Mateo, I., and W. J. Tobias. 2004. Survey of nearshore fish communities on tropical backreef lagoons on the southeastern coast of St. Croix. Caribbean Journal of Science $40: 327-342$

Mathis, A., and D. P. Chivers. 2003. Overriding the oddity effect in mixed-species aggregations: group choice by armored and nonarmored prey. Behavioral Ecology 14:334-339.

Mathis, A., and R. J. F. Smith. 1993. Intraspecific and cross-superorder responses to chemical alarm signals by brook stickleback. Ecology 74:2395-2404

McAdam, A. G., and D. L. Kramer. 1998. Vigilance as a benefit of intermittent locomotion in small mammals. Animal Behaviour 55:109-117.

McNamara, J. M., and S. R. X. Dall. 2010. Information is a fitness enhancing resource. Oikos 119:231-236.

Meise, K., D. W. Franks, and J. Bro-Jørgensen. 2018. Multiple adaptive and non-adaptive processes determine 
responsiveness to heterospecific alarm calls in African savannah herbivores. Proceedings of the Royal Society B 285:20172676.

Mirza, R. S.. 2003. Fathead minnows learn to recognize heterospecific alarm cues they detect in the diet of a known predator. Environmental Biology of Fishes 66:321-327.

Moland, E., J. V. Eagle, and G. Jones.2005.Ecology and evolution of mimicry in coral reef fishes. Pages 455-482 in Oceanography and marine biology: an annual review. CRC Press, Boca Raton, Florida, USA.

Morueta-Holme, N., B. Blonder, B. Sandel, B. J. McGill, R. K. Peet, J. E. Ott, C. Violle, B. J. Enquist, P. M. Jørgensen, and J.-C. Svenning. 2016. A network approach for inferring species associations from co-occurrence data. Ecography 39:1139-1150.

Mumby, P. J., A. J. Edwards, E. P. Green, C. W. Anderson, A. C. Ellis, and C. D. Clark. 1997. A visual assessment technique for estimating seagrass standing crop. Aquatic Conservation: Marine and Freshwater Ecosystems 7:239-251.

Nagelkerken, I., M. Dorenbosch, W. C. E. P. Verberk, E. Cocheret de la Morinière, and G. van der Velde. 2000. Importance of shallow-water biotopes of a Caribbean bay for juvenile coral reef fishes: patterns in biotope association, community structure and spatial distribution. Marine Ecology Progress Series 202:175-192.

Newman, S. P., R. D. Handy, and S. H. Gruber. 2007. Spatial and temporal variations in mangrove and seagrass faunal communities at Bimini, Bahamas. Bulletin of Marine Science 80:529-553.

Ogden, J. C., and P. R. Ehrlich. 1977. The behavior of heterotypic resting schools of juvenile grunts (Pomadasyidae). Marine Biology 42:273-280.

Olson, M. H., G. G. Mittelbach, and C. W. Osenberg. 1995. Competition between predator and prey: resource-based mechanisms and implications for stage-structured dynamics. Ecology 76:1758-1771.

Orpwood, J. E., A. E. Magurran, J. D. Armstrong, and S. W. Griffiths. 2008. Minnows and the selfish herd: effects of predation risk on shoaling behaviour are dependent on habitat complexity. Animal Behaviour 76:143-152.

Ovaskainen, O., N. Abrego, P. Halme, D. Dunson, and D. Warton. 2016. Using latent variable models to identify large networks of species-to-species associations at different spatial scales. Methods in Ecology and Evolution 7:549-555.

Ovaskainen, O., G. Tikhonov, A. Norberg, F. Guillaume Blanchet, L. Duan, D. Dunson, T. Roslin, and N. Abrego. 2017. How to make more out of community data? A conceptual framework and its implementation as models and software. Ecology Letters 20:561-576.

Overholtzer, K. L., and P. J. Motta. 2000. Effects of mixedspecies foraging groups on the feeding and aggression of juvenile parrotfishes. Environmental Biology of Fishes 58:345-354.

Parmentier, E., K. Mann, and D. Mann. 2011. Hearing and morphological specializations of the mojarra (Eucinostomus argenteus). Journal of Experimental Biology 214:2697-2701.

Parrish, J. D. 1989. Fish communities of interacting shallow-water habitats in tropical oceanic regions. Marine Ecology Progress Series 58:143-160.

Peters, R. H.1986. The ecological implications of body size. Cambridge University Press, Cambridge, UK.

Pitcher, T. J., and A. C. House. 1987. Foraging rules for group feeders: area copying depends upon food density in shoaling goldfish. Ethology 76:161-167.

Plummer, M.2003.JAGS: A program for analysis of Bayesian graphical models using Gibbs sampling. In Proceedings of the 3rd International Workshop on Distributed Statistical Computing, Vienna, Austria.
Polis, G. A., and R. D. Holt. 1992. Intraguild predation: The dynamics of complex trophic interactions. Trends in Ecology \& Evolution 7:151-154.

Pollock, L. J., R. Tingley, W. K. Morris, N. Golding, R. B. O'Hara, K. M. Parris, P. A. Vesk, M. A. McCarthy, and J. McPherson. 2014. Understanding co-occurrence by modelling species simultaneously with a joint species distribution model (JSDM). Methods in Ecology and Evolution 5:397406.

Popovic, G. C., D. I. Warton, F. J. Thomson, F. K. C. Hui, and A. T. Moles. 2019. Untangling direct species associations from indirect mediator species effects with graphical models. Methods in Ecology and Evolution 10:1571-1583.

Randall, J. E. 1967. Food habits of reef fishes of the West Indies. Studies in Tropical Oceanography 5:665-847.

Rieucau, G., P. Blanchard, J. G. A. Martin, F.-R. Favreau, A. W. Goldizen, and O. Pays. 2012. Investigating differences in vigilance tactic use within and between the sexes in eastern grey kangaroos. PLoS ONE 7:e44801.

Rodgers, G. M., H. Kimbell, and L. J. Morrell. 2013. Mixedphenotype grouping: the interaction between oddity and crypsis. Oecologia 172:59-68.

Rodgers, G. M., J. R. Ward, B. Askwith, and L. J. Morrell. 2011. Balancing the dilution and oddity effects: decisions depend on body size. PLoS ONE 6:e14819.

Rudolf, V. H. W., and N. L. Rasmussen. 2013a. Ontogenetic functional diversity: Size structure of a keystone predator drives functioning of a complex ecosystem. Ecology 94:10461056.

Rudolf, V. H. W., and N. L. Rasmussen. 2013b. Population structure determines functional differences among species and ecosystem processes. Nature Communications 4:2318.

Ryer, C. H., and B. L. Olla. 1992. Social mechanisms facilitating exploitation of spatially variable ephemeral food patches in a pelagic marine fish. Animal Behaviour 44:69-74.

Sazima, I. 1986. Similarities in feeding behaviour between some marine and freshwater fishes in two tropical communities. Journal of Fish Biology 29:53-65.

Sazima, I. 2002. Juvenile snooks (Centropomidae) as mimics of mojarras (Gerreidae), with a review of aggressive mimicry in fishes. Environmental Biology of Fishes 65:37-45.

Sazima, C., J. P. Krajewski, R. M. Bonaldo, and P. R. Guimaraes. 2006. The goatfish Pseudupeneus maculatus and its follower fishes at an oceanic island in the tropical west Atlantic. Journal of Fish Biology 69:883-891.

Scharf, F. S., F. Juanes, and R. A. Rountree. 2000. Predator size-prey size relationships of marine fish predators: interspecific variation and effects of ontogeny and body size on trophic-niche breadth. Marine Ecology Progress Series 208:229-248.

Schmidt, T. W. 1989. Food habits, length-weight relationship and condition factor of young great barracuda, Syphraena barracuda (Walbaum), from Florida Bay, Everglades National Park, Florida. Bulletin of Marine Science 44:163170.

Schmidt, K. A., S. R. X. Dall, and J. A. van Gils. 2010. The ecology of information: an overview on the ecological significance of making informed decisions. Oikos 119:304-316.

Schmitt, M. H., K. Stears, C. C. Wilmers, and A. M. Shrader. 2014. Determining the relative importance of dilution and detection for zebra foraging in mixed-species herds. Animal Behaviour 96:151-158.

Schmitt, M. H., K. Stears, and A. M. Shrader. 2016. Zebra reduce predation risk in mixed-species herds by eavesdropping on cues from giraffe. Behavioral Ecology 27:1073-1077.

Searcy, W. A., and S. Nowicki.2005. The evolution of animal communication: reliability and deception in signaling 
systems. Princeton University Press, Princeton, New Jersey, USA.

Seppänen, J.-T., J. T. Forsman, M. Mönkkönen, and R. L. Thomson. 2007. Social information use is a process across time, space, and ecology, reaching heterospecifics. Ecology 88:1622-1633.

Serafy, J. E., C. H. Faunce, and J. J. Lorenz. 2003. Mangrove shoreline fishes of Biscayne Bay, Florida. Bulletin of Marine Science 72:161-180.

Sogard, S. M.. 1997. Size-selective mortality in the juvenile stage of teleost fishes: a review. Bulletin of Marine Science 60:1129-1157.

Sridhar, H., G. Beauchamp, and K. Shanker. 2009. Why do birds participate in mixed-species foraging flocks? A largescale synthesis. Animal Behaviour 78:337-347.

Sridhar, H., et al. 2012. Positive relationships between association strength and phenotypic similarity characterize the assembly of mixed-species bird flocks worldwide. American Naturalist 180:777-790.

Sridhar, H., F. Jordán, and K. Shanker. 2013. Species importance in a heterospecific foraging association network. Oikos $122: 1325-1334$

Srinivasan, U., R. H. Raza, and S. Quader. 2010. The nuclear question: rethinking species importance in multi-species animal groups. Journal of Animal Ecology 79:948-954.

Thiollay, J.-M., and M. Jullien. 1998. Flocking behaviour of foraging birds in a neotropical rain forest and the antipredator defence hypothesis. Ibis 140:382-394.

Thrush, S. F., R. D. Pridmore, J. E. Hewitt, and V. J. Cummings. 1992. Adult infauna as facilitators of colonization on intertidal sandflats. Journal of Experimental Marine Biology and Ecology 159:253-265.

Thrush, Simon F., G. Coco, and Judi E. Hewitt. 2008. Complex positive connections between functional groups are revealed by neural network analysis of ecological time series. American Naturalist 171:669-677.

Tosh, C. R., A. L. Jackson, and G. D. Ruxton. 2007. Individuals from different-looking animal species may group together to confuse shared predators: simulations with artificial neural networks. Proc Biol Sci 274:827-832.

Ulrich, W., and N. J. Gotelli. 2010. Null model analysis of species associations using abundance data. Ecology 91:3384-3397.

UNEP-WCMC, WorldFish Centre, WRI, TNC2010.Global distribution of warm-water coral reefs, compiled from multiple sources including the Millennium Coral Reef Mapping
Project. Version 1.3. Includes contributions from IMaRSUSF and IRD (2005), IMaRS-USF (2005), and Spalding et al. (2001).UNEP World Conservation Monitoring Centre, Cambridge, UK.

Valone, T. J., and J. J. Templeton. 2002. Public information for the assessment of quality: a widespread social phenomenon. Philosophical Transactions of the Royal Society of London B Biological Sciences 357:1549-1557.

Veech, J. A., and M. Araújo. 2014. The pairwise approach to analysing species co-occurrence. Journal of Biogeography 41:1029-1035.

Ward, A. J. W., J. E. Herbert-Read, D. J. T. Sumpter, and J. Krause. 2011. Fast and accurate decisions through collective vigilance in fish shoals. Proceedings of the National Academy of Sciences 108:2312-2315.

Warton, D. I., F. G. Blanchet, R. B. O'Hara, O. Ovaskainen, S. Taskinen, S. C. Walker, and F. K. C. Hui. 2015. So many variables: joint modeling in community ecology. Trends in Ecology \& Evolution 30:766-779.

Wasserman, S., and K. Faust.1994. Social network analysis: Methods and applications. Cambridge University Press, Cambridge, UK.

Webb, C. O., D. D. Ackerly, M. A. McPeek, and M. J. Donoghue. 2002. Phylogenies and community ecology. Annual Review of Ecology and Systematics 33:475-505.

Werner, E. E., and J. F. Gilliam. 1984. The ontogenetic niche and species interactions in size-structured populations. Annual Review of Ecology and Systematics 15:393-425.

Wilson, D. S.. 1975. The adequacy of body size as a niche difference. American Naturalist 109:769-784.

Wissinger, S. A.. 1992. Niche overlap and the potential for competition and intraguild predation between size-structured populations. Ecology 73:1431-1444.

Wisz, M. S., et al. 2013. The role of biotic interactions in shaping distributions and realised assemblages of species: implications for species distribution modelling. Biological Reviews of the Cambridge Philosophical Society 88:15-30.

Wolf, N. G. 1985. Odd fish abandon mixed-species groups when threatened. Behavioral Ecology and Sociobiology 17:47-52.

Wolters, S., and K. Zuberbühler. 2003. Mixed-species associations of Diana and Campbell's monkeys: the costs and benefits of a forest phenomenon. Behaviour 140:371-385.

Woodward, G., and A. G. Hildrew. 2002. Body-size determinants of niche overlap and intraguild predation within a complex food web. Journal of Animal Ecology 71:1063-1074.

\section{SUPPORTING INFORMATION}

Additional supporting information may be found in the online version of this article at http://onlinelibrary.wiley.com/doi/ 10.1002/ecy.2920/suppinfo 